\title{
Long-term effects of participation in the Baltimore City drug treatment court: Results from an experimental study
}

\author{
DENISE C. GOTTFREDSON, STACY S. NAJAKA, BROOK W. KEARLEY \\ and CARLOS M. ROCHA \\ Department of Criminology and Criminal Justice, The University of Maryland, 2220D LeFrak Hall, \\ College Park, MD 20742, USA \\ *corresponding author: E-mail:dgottfredson@crim.umd.edu
}

\begin{abstract}
This study uses an experimental design comparing 235 offenders assigned either to drug treatment court or treatment as usual. It extends prior analyses of this study sample to examine whether differences observed between drug treatment court subjects and control subjects at one and two years after the start of the program persist after three years, when many of the subjects had ceased active treatment. Further, it extends earlier analyses that showed that the quantity of drug treatment court services received was related to lower recidivism rates by using an instrumental variables approach to handle the endogeneity problem that sometimes arises when subjects self-select into different levels of service. Results show a sustained treatment effect on recidivism, controlling for time at risk. This effect is not limited to the period during which services are delivered. Rather, it persists even after participation in the drug court program ceases. Results also show that the recidivism is lowest among subjects who participate at higher levels in certified drug treatment, status hearings, and drug testing. These positive findings are tempered with findings that more than three-fourths of clients are re-arrested within three years, regardless of participation in the drug treatment court, and that drug treatment court cases spend approximately the same number of days incarcerated as do control cases. Implications for strengthening drug treatment courts are discussed.
\end{abstract}

Key words: drug treatment courts, randomized experiment

\section{Introduction}

Drug treatment courts (DTCs) were first developed in the late 1980s in response to a justice system overburdened by drug crimes. Various social and political forces during that time - most importantly, the crack cocaine epidemic and the subsequent 'war on drugs' - created an environment in which court dockets were overwhelmed by drug cases and prisons were filled to capacity with drug offenders (Belenko 1993; McColl 1996; Tonry 1995). Practitioners and reformers, impressed with positive results found in the drug treatment literature (Collins and Allison 1983; Wish and Johnson 1986; Anglin and Hser 1990), advanced drug treatment as a strategy to deal with the U.S. drugs/crime problem, and in 1989, the first drug treatment court was instituted in Dade County, Florida (USDOJ 1998).

Since that time, DTCs have enjoyed wide support, with the number of courts growing to over 1,000 nationally (Office of Justice Programs Drug Court Clearinghouse and Technical Assistance Project 2004). Internationally, the DTC model has also been adopted by countries such as Canada, Australia, and the UK (Harrison and Scarpitti 2002). Most DTCs involve prompt identification and 
placement of eligible offenders, a non-adversarial approach among prosecution and defense counsel, integration of drug treatment services with justice system case processing, frequent drug and alcohol testing, frequent status hearings with the judge, and intensive drug treatment (Drug Courts Program Office 1997). This combination of sanctions, drug treatment, and probation services is expected to reduce levels of substance use and crime as well as improve offender integration into the community by enhancing mental and physical health, social connections, and employment.

Much of the existing DTC research and evaluation reports high retention rates and positive outcomes, including criminal justice cost-savings and reductions in crime, drug use and welfare use (Belenko 1998, 1999, 2001; Finigan 1999; Goldkamp and Weiland 1993; Goldkamp et al. 2001a, b; Harrell et al. 1998; Gottfredson and Exum 2002; Gottfredson et al. 2003a, c; Hora et al. 1999; Sechrest et al. 1998; Spohn et al. 2001; Wilson et al. 2002). A meta-analysis of 41 independent evaluations of drug courts (Wilson et al. 2002) concludes that drug courts reduce crime and drug use to a practically meaningful degree, despite concerns about the unreliability of the evidence related to the performance and outcomes of federally-funded drug treatment courts (U.S. General Accounting Office 2002). Many of the individual studies of drug treatment courts, however, are small-scale evaluations which suffer from a number of limitations, including a reliance on pre-post designs for the treatment group only and post-only comparisons of the treatment group with dissimilar comparison groups (Belenko 2001; U.S. General Accounting Office 1997; Wilson et al. 2002). However, studies that compare recidivism rates of drug court clients with those of similar groups of clients who did not receive drug court services generally report more favorable outcomes for drug treatment court clients (Finigan 1999; Goldkamp and Weiland 1993; Gottfredson et al. 1997; Peters and Murrin 1998; Sechrest et al. 1998).

A few studies have randomly assigned clients to receive drug court services or not. Results from one of these experiments, the Baltimore City Drug Treatment Court (BCDTC), are summarized below. In another randomized experiment, Deschenes et al. (1995) compared randomly assigned drug court participants to three samples with varying levels of drug testing coupled with supervision and found that drug court participants recidivated at approximately the same rates as the comparison group samples. In this study, the drug court participants were more involved in treatment and counseling during the one-year follow-up period, but less involved in other constructive activities such as employment, community service, payment of fines and restitution, and formal education than the controls, suggesting that the treatment component of the program was not highly effective. Harrell et al. (1998) evaluated a pretrial drug court by comparing offenders who were randomly assigned to receive either drug treatment, drug testing, and judicial monitoring (the drug court); drug testing with graduated sanctions and judicial monitoring; or drug testing and judicial monitoring only. The defendants on both the drug court docket and the docket which included graduated sanctions were significantly less likely to test positive for drugs in the month before sentencing compared with offenders who were not subject to sanctions for noncompliance. These latter two studies 
suggest that programs including drug testing and sanctions may be as effective as programs that also involve mandatory treatment, although in both studies the treatment component was poorly implemented. In a study involving survival analysis, Peters and Murrin (1998) found that the length of time in drug treatment was significantly related to the number of arrests for both drug court graduates and nongraduates, suggesting that treatment is an important element of the drug court model.

These studies have raised important questions about the mechanisms contributing to the effectiveness of drug courts (Longshore et al. 2001). While research has generally concluded that drug courts are effective, precisely why and for whom drug courts work remains largely unknown. The populations involved in the studies to date have varied considerably from moderate drug users to the seriously addicted. A recent study of drug courts in two sites assessed the impact of five drug court elements on four outcome measures (Goldkamp et al. 2001a, b). Indicators of the drug court elements included two measures of participation in treatment, two measures of assignment of sanctions, and the number of court appearances. Outcome measures included graduation, any type of re-arrest, re-arrest for a drug offense, and re-arrest for a non-drug offense. Analyses controlling for risk-related participant attributes produced findings that were both site and outcome variable dependent. Clearly, additional research is needed to better understand the essential elements of the drug court model, and how these elements may differ for different populations. Also, only two studies (Deschenes et al. 1995; Goldkamp et al. 2001a, b) have followed up both DTC clients and control subjects for as long as three years, and few studies have documented continuing DTC effects after the end of active treatment. In fact, none of the studies that used random assignment to treatment and control conditions distinguished between in-program and postprogram recidivism (Belenko 2001).

This study addresses some of the weaknesses of prior research. The current research incorporates an experimental design to examine whether differences already observed between drug treatment court subjects and control subjects at one and two years after the start of the program persist after three years, when many of the subjects had ceased active treatment. It compares in-program and post-program recidivism rates. Further, it relates variability in recidivism to variability in the quantity of specific DTC services received using an instrumental variables approach.

\section{The Baltimore City Drug Treatment Court ${ }^{1}$}

The Baltimore City Drug Treatment Court (BCDTC) was established in 1994, largely in response to a report by the Bar Association of Baltimore City (1990) which estimated that nearly $85 \%$ of all crimes committed in Baltimore were addiction-driven. Drug court clients are referred from one of two tracks: (1) Circuit Court felony cases supervised by Parole and Probation and (2) District Court misdemeanor cases supervised by Parole and Probation. These two tracks are postconviction tracks, whereby clients generally enter the drug court program as a condition of probation. 
In order to be considered for the drug court program, defendants must satisfy several eligibility requirements. They must be at least 18 years of age, reside in Baltimore City, and cannot have any past or current convictions for violent offenses. Once these initial conditions have been met, the process of identifying drug court clients follows several steps. Eligible defendants who express an interest in the program meet with the Public Defender to discuss their possible participation. If after this meeting the defendant remains interested in the drug court program, record checks are completed and reviewed by the State's Attorney. The State's Attorney then meets with the Public Defender to determine which defendants would be best served by the program. Among this subset of defendants, the Psychopathy Checklist (Hare et al. 1990) is administered to evaluate the offenders' suitability for the program, and the Addiction Severity Index (McLellan et al. 1992) is administered to assess their motivation and need for treatment. Both tests are administered by personnel in the Drug Court Assessment Unit. Data regarding drug history, medical history, employment status, as well as other aspects of the defendants' families and social relations are also collected. Upon the completion of these assessments, the assessor recommends the defendants for the program, or not. The names of eligible defendants are submitted to the drug court docket. The State's Attorney, Public Defender, probation agent, and the defendant then appear before the drug court judge to discuss the case. The judge renders the final decision as to the offender's placement in the drug court program.

\section{Program components}

The BCDTC program combines intensive supervision, drug testing, drug treatment, and judicial monitoring over the course of approximately two years. All defendants enter the program under intensive supervision. The guidelines of the drug court recommend (1) a minimum of three face-to-face contacts per month between defendants and probation officers, (2) two home-visits per month, and (3) verification of employment status once per month. In addition, agents frequently verify other special conditions of probation and regularly review their clients' criminal records for recent violations. As defendants near graduation from the drug court program, their level of supervision is downgraded from 'intensive' to 'standard high,' which requires fewer contacts.

During the course of their supervision, drug court clients are frequently drug tested. Prior to October of 1998, the frequency of testing varied depending on the clients' test results. All clients were initially required to submit two urine samples per week (referred to as phase I testing). After completing one month with no positive tests, clients generally graduated to phase II testing in which tests were completed once every week. After two consecutive months of clean tests, clients progressed to phase III testing. During phase III, clients were required to complete one urinalysis every two weeks, and continued at this rate for the duration of the program. In October of 1998, the testing schedule was revised to reflect a more structured and less individualized schedule. As of that date, all clients are required to provide two urine samples per week for the first three months of the program. 
During the next three months, tests are completed once per week. Clients are then tested once per month for a period of six months. After that time, urinalyses are completed randomly for as long as the client remains under drug court supervision.

In addition to supervision and drug testing, drug court program participants are required to receive treatment from one of eight providers located in the city of Baltimore. Three of the programs provide intensive outpatient services; two provide methadone maintenance; two provide inpatient care; and one provides transitional housing. Drug court clients are assigned to a program based on the type of treatment required, the treatment center's availability, and the location of the treatment center relative to the client's residence.

Throughout the program, a drug court judge monitors the defendants' progress through regularly scheduled status hearings. Defendants are required to attend status hearings once every two weeks. At these hearings, the judge reviews reports from the probation agent regarding the defendants' compliance with the program. Based on these reports, the judge prescribes graduated sanctions as needed. Sanctions usually involve increased contacts with the probation agent, increased status hearings, or increased drug testing. Severe violations generally lead to a violation of probation hearing, during which the judge may re-impose the original sentence which was suspended pending successful completion of the drug court program.

Drug court clients become eligible for graduation upon satisfactory completion of the prescribed treatment and compliance with the requirements of supervision. The decision to graduate a defendant must be approved by the Court, the State's Attorney's Office, and the Office of the Public Defender. A graduation ceremony is held to mark the occasion, and defendants' friends and family are encouraged to attend.

\section{Comparison with other drug courts}

The BCDTC does not differ substantially from the 'typical' drug court in terms of its components. According to recent self-reports of operating drug courts (Office of Justice Programs Drug Court Clearinghouse and Technical Assistance Project 2001 ), $60 \%$ of adult drug courts involve participants both post-conviction and at some other point (e.g., pretrial, probation violators), as did Baltimore during the period covered by this study. Results from an earlier survey of drug courts (Cooper 1997) showed that the typical drug court screens clients for substance use, assigns clients to treatment provided by community-based organizations, requires at least three contacts per week with the treatment provider, two urine tests per week, and weekly or bi-weekly contact with the drug court judge in the initial phases. The typical drug court uses increased frequency of court status hearings, urinalysis, and treatment as sanctions for relapse, and $60 \%$ use short periods of incarceration. Finally, the typical drug court imposes incarceration sentences on defendants who are unsuccessfully terminated from the program. The Baltimore drug court is like the typical drug court on these dimensions. It is atypical primarily in the type of 
population it serves (mostly African American male heroin addicts), and the active involvement of the Division of Parole and Probation in the operation of the program. For example, initial screening for substance use problems is conducted by this division in Baltimore, but only in $16 \%$ of drug courts nationwide. Also, intensive probation supervision is an element of the BCDTC but is not generally found elsewhere. Other unusual aspects of the BCDTC include its large size (as of Spring, 2001, 1,218 clients had either graduated or were currently enrolled) and the extensive screening conducted prior to program participation.

\section{Prior research on the Baltimore City Drug Treatment Court}

Several reports on the success of the BCDTC have been published. Gottfredson et al. (1997) reported the results of an evaluation of the early stages of the BCDTC. In that evaluation, the first 145 offenders assigned to the BCDTC were compared to a group of more than 500 offenders receiving traditional parole and probation services. This short-term (six-month) quasi-experimental evaluation found that after controlling for pre-existing differences across the treatment and comparison groups, participation in the BCDTC program was associated with a $50 \%$ decrease in the odds of re-arrest for a new offense. However, the researchers concluded that a more rigorous evaluation was needed in order to yield conclusive results.

A randomized experiment of the BCDTC (to be described shortly) began in 1997. The first report from this more rigorous study compared the DTC cases with control cases 12 months post-randomization and reported that the drug treatment court subjects were significantly less likely than control subjects to be arrested for new offenses (Gottfredson and Exum 2002). Specifically, 63.5\% of control cases were arrested for new offenses versus $48.2 \%$ of drug treatment court cases. The drug treatment court sample also had significantly fewer arrests ( 0.9 vs. 1.3) and significantly fewer charges (1.6 vs. 2.4), as compared to controls. Effects favored the DTC cases for every type of crime examined (except prostitution), but were statistically significant only for violent and sex charges. Findings from the second year of the study showed sustained treatment differences with regard to recidivism (Gottfredson et al. 2003c). Specifically, 66.2\% of drug treatment court and 81.3\% of control subjects were arrested for a new offense. The number of new arrests (1.6 vs. 2.3) and new charges (3.1 vs. 4.6) were also significantly lower for treatment than control group members, and these difference remained significant even after taking into account time not at risk during the follow-up period due to incarceration. Effects favored the DTC cases for every type of crime examined, but were statistically significant only for drug-related crime charges. This study also compared DTC subjects who participated in treatment with those who did not and with control subjects and reported the treated drug court subjects were significantly less likely to recidivate than both untreated drug court subjects and control subjects.

Survival analyses examining time to rearrest in the first 24 months following randomization showed that assignment to the drug court significantly increased 
time to rearrest (Banks and Gottfredson 2004). When the survival functions were examined separately for drug court cases who actually received drug treatment services and those who did not, again the results showed that attending treatment significantly decreased the risk of failure over a two-year follow-up period (Banks and Gottfredson 2003).

The most recent published reports from the evaluation of the BCDTC (Gottfredson et al. 2003a) report results from interviews with a subset of the research subjects who were interviewed during the follow-up period. These analyses demonstrated that the positive program effects on crime are replicated with self-reports. In addition, program participants reported less substance use than controls. Few differences between groups were observed on other outcomes including employment, education, mental and physical health, and family and social relationships, although treatment cases were less likely than controls to be on the welfare rolls at the time of the interview.

Taken together, this prior research on the BCDTC has demonstrated that a DTC focusing on a high-rate offending drug-addicted urban population reduces crime and drug use in this population, and that these positive effects persist for at least two years. However, the magnitude of the differences in recidivism rates are not large, the re-arrest rates for DTC clients are high, and, although differences favor DTC cases in all recidivism analyses, the effects in the most recent analysis reach statistical significance only for drug-related crimes. The research also suggests that there is much variability in the quality of services received by DTC clients, and that receiving drug treatment may be important. The research on the importance of drug treatment, however, does not entirely rule out selection effects as an alternative explanation for the better outcomes observed for subjects who happened to receive more drug treatment services. Further, the prior research does not examine (a) variability in outcomes related to other key elements of the DTC (e.g., drug testing and judicial hearings), or (b) the extent to which positive effects persist after subjects have stopped receiving DTC services. As noted earlier, the intent of the DTC model is to break the cycle of drugs and crime. Several of the key elements in the model are designed to provide social and personal supports so that clients will be able to maintain a drug-free lifestyle after the program ends, thereby reducing criminal activity in the longer term. Unless the effect of participation in a DTC program can be shown to extend beyond the period during which services are provided, questions about the utility of the model for achieving the intended effects will persist. This paper seeks to fill these gaps in knowledge about the effectiveness of the BCDTC.

\section{Methodology}

\section{Design}

The evaluation of the BCDTC utilizes an experimental research design. Beginning in February of 1997, eligible drug court offenders were randomly assigned to the 
drug treatment court or to treatment as usual. Assignment occurred just prior to the appearance before the drug court judge. The randomization results were given to the judge as a recommendation and were followed in most cases because the judges had agreed to participate in the study. Randomization continued through August of 1998, at which time 235 clients had been assigned randomly to one of the two conditions. Study participants were randomly assigned at a ratio of one treatment to one control for Circuit Court cases and at a ratio of two treatment to one control for District Court cases. This was done at the request of the District Court judge who was concerned that all drug treatment court slots might not be filled if we kept with a one-to-one ratio. Of the 139 cases randomly assigned to the treatment group, we found records to indicate that $91 \%$ were actually dealt with in the drug treatment court. In comparison, approximately $7 \%$ of the 96 cases randomly assigned to the control condition were dealt with in the drug treatment court.

Data

All of the data for this study are from official records of the Maryland Department of Public Safety and Correctional Services and the Baltimore Substance Abuse Systems, Inc. (BSAS), an organization that coordinates drug treatment services in Baltimore. Data were collected on demographic characteristics and prior offense history, as well as recidivism, drug treatment, drug testing, probation supervision, judicial monitoring, and time spent incarcerated in jail and prison through three years following randomization. ${ }^{2}$ Note that the measures of participation in the DTC components were fairly superficial, measuring, for example, the duration of drug treatment rather than the content or quality of this treatment.

\section{Analysis}

In all analyses of the effects of the full DTC intervention, subjects were treated as randomized, regardless of their actual treatment. That is, subjects randomly assigned to the drug court were analyzed as members of the treatment group regardless of their actual treatment, and subjects randomly assigned to the control group were analyzed as members of the control group regardless of their actual treatment. This conservative strategy, called an 'intent-to-treat' (ITT) analysis, was adopted to preserve the comparability of the study groups.

Means and proportions were computed for the outcomes of interest for the DTC and control cases. ${ }^{3}$ These differences in the means and proportions were also examined by originating court because for some variables, the treatment effect was found to interact with originating court. OLS regression was used to provide significance tests for the DTC/control group comparisons on continuous outcome measures, and logistic regression was used to compare the two groups on dichotomous outcomes. Independent variables in the regression equations included 
condition (drug court or control), originating court (District or Circuit), and a condition-by-court interaction term. Originating court was included to control for the fact that different ratios of treatment to control cases were used in the randomization procedure in the two courts (see above), which resulted in a correlation between treatment condition and court. A condition by court interaction term allowed us to ascertain whether program outcomes differed by originating court. If the results of the regression indicated that the condition-by-court interaction was not significant, the regression equation was re-estimated without the interaction term. For comparisons of treatment and control cases within court, simple chi-square (for dichotomous outcomes) and $t$-tests (for continuous outcomes) were used to test for the significance of the differences.

An instrumental variables (IV) approach (Angrist 2005; Wooldridge 2002) was also used to estimate the effects on recidivism of the level of participation in various components of the BCDTC. As noted earlier, Gottfredson et al. (2003c) compared DTC subjects who participated in treatment with those who did not and with control subjects and reported the treated drug court subjects were significantly less likely to recidivate than both untreated drug court subjects and control subjects. They cautioned, however, against interpreting that finding to suggest that increased drug treatment reduces crime because unmeasured factors that lead individuals to seek more treatment may also lead them to commit less crime. This type of omitted variable problem, unless corrected, would result in a biased estimate of the effect of treatment on crime. Banks and Gottfredson (2003) attempted to rule out these selection artifacts in the association of participation and recidivism by using statistical controls for demographic characteristics and prior offending. These statistical controls, however, were limited and could not allow the researchers to confidently rule out selection effects. The present analysis uses the two-stage least squares (2SLS) approach to lend further support to causal interpretations of the effects of participation in program components of the BCDTC.

The 2SLS approach - a common form of the more general IV approach recognizes that the level of client participation in drug court components is likely to be correlated with the disturbance terms in the OLS regression equation predicting the number of arrests. ${ }^{4}$ Under such conditions, an important assumption is violated and OLS yields inconsistent estimators. ${ }^{5}$ In IV terminology, the independent variable of interest is considered a 'problematic causal variable' because it is correlated with the disturbance term for the dependent variable. IV solves this problem by locating a variable that is both uncorrelated with the disturbance term in the equation of interest and correlated with the problematic causal variable (once the effects of other variables in the equation have been netted out). A variable that meets these conditions is called an IV for the problematic causal variable and is used to essentially remove from the problematic causal variable the portion of variance that is correlated with the disturbance term. This new 'cleaned up' independent variable is no longer problematic and can be used in a subsequent step to estimate the effect of the independent variable of interest. Although locating an IV that meets the required assumptions can be challenging, 
we are fortunate in this study to have an ideal instrument: the variable indicating random assignment to treatment and control conditions. This variable is by definition uncorrelated with the disturbance term in the equation of interest, and it is highly correlated with the level of participation in drug testing, drug treatment, and judicial hearings (although not to the amount of probation supervision received, as will be shown shortly). Angrist (2005) demonstrates the use of the IV method to estimate the effects of treatment in the context of an imperfectly implemented randomized experiment - the Minneapolis Domestic Assault experiment. In his example, approximately $20 \%$ of the cases randomized to receive 'coddling' as opposed to arrest as a response to domestic violence were actually arrested. Any attempt to estimate the effect of 'coddling' on re-arrest using the actual services received will be biased to the extent that the factors that led police to over-ride the randomization protocol are correlated with re-arrest during the follow-up period. Angrist uses the random assignment variable as an instrument to obtain a corrected estimate of the effect of "coddling" (versus arrest) on subsequent crime.

Our use of the IV approach is similar, but uses 2SLS to execute the analysis. As the name implies, 2SLS involves two stages (or more specifically, two regression equations). In the first regression equation, the problematic causal variable is regressed on the instrumental variable(s) and the other determinants of the outcome of interest (i.e., explanatory variables). The resulting coefficients are then used to create a predicted value of the problematic causal variable for each member of the sample. These predicted values include participation induced by random assignment and the other measured covariates, and exclude participation induced by unmeasured factors that might be correlated with recidivism. In the second regression equation, the outcome of interest is regressed on the predicted values of the problematic causal variables and the other determinants of the outcome of interest used in the first equation. Covariates are typically added to both the first and second regression equations for efficiency gain (see Angrist 2005), and the same covariates must be added to the two equations. However, when 2SLS estimates are obtained by running OLS twice, the standard errors will be too large because they are based on the residual sum of squares from the second equation rather than the first. To obtain accurate standard errors, one must calculate the residual sum of squares using the actual value of the regressor after obtaining parameter estimates using the predicted value (Foster and McLanahan 1996). Most statistical packages with a 2SLS procedure automatically perform this correction.

In the current study, 2SLS analyses were conducted in SPSS 11.0 for Windows for the problematic participation variables. ${ }^{6}$ These analyses essentially created a new participation variable by predicting it from originating court, age, gender, race, number of prior offenses, number of days at risk for a new arrest, and the random treatment assignment variable (the IV). The predicted outcome from this equation contains only the variability in the original implementation variable that is uncorrelated with the error term in the recidivism equation. In the second stage, the number of arrests was regressed on the newly created implementation variable from the first stage and the same control variables included in the equation that 
produced the predicted implementation variable in stage one. The 2SLS procedure also performs a necessary correction to the standard errors. The coefficient for the corrected implementation variable in the 2 SLS solution provides a consistent and unbiased estimate of the effect of participation in the drug treatment court components, assuming that the disturbance on the dependent variable is independent of the IV (random assignment) and that the IV effects the number of arrests only via the participation variable.

\section{Results}

\section{Study participants}

The participants in this study include the 235 arrestees who were assigned randomly to receive either BCDTC services $(N=139)$ or treatment as usual in the traditional court $(N=96)$. Of the 139 cases assigned to the treatment condition, 84 were handled in the District Court and 55 were handled in the Circuit Court. Of the 96 cases assigned to the control condition, 42 were handled in the District Court and 54 were handled in the Circuit Court. The study participants are all adults, with an average age of 35 . Approximately $89 \%$ are African American and $74 \%$ are male. The study subjects have considerable criminal histories. At the time of randomization into the study, the drug court subjects averaged 12 prior arrests, while control subjects averaged 11 prior arrests. Both groups averaged five prior convictions. Comparisons between the two study groups on these background characteristics produced no statistically significant differences, indicating that the randomization procedure produced similar groups.

In addition to considerable criminal histories, the study subjects had considerable drug problems. In an earlier evaluation using the same sample, Gottfredson et al. (2003c) summarized Addiction Severity Index data for the drug court subjects based on interviews conducted either by assessment staff prior to randomization or by treatment staff upon entry into treatment. Nearly all (96\%) of the drug court sample named heroin or cocaine as their primary drug of choice, and more than half $(60 \%)$ reported using crack, cocaine, or heroin three or more times per week. These data make clear that unlike some drug courts that serve lower risk offenders whose drug use is not severe, the BCDTC serves a drug-addicted population.

\section{Graduation status and program length}

By the end of the three-year follow-up period, 43 (31\%) of the drug court cases had graduated from drug court after spending, on average, nearly 22 months (665 days) participating in the drug court program. Of the remaining 96 cases randomized to the drug court condition, $15(11 \%)$ were still participating or had an open probation case associated with the drug court; $62(45 \%)$ had been terminated from the drug court program due to noncompliance after spending, on average, almost 17 months 
(509 days) participating in the program; four (3\%) died prior to completing the drug court program; the status of two subjects $(1 \%)$ could not be determined; and, as noted above, the remaining 13 subjects $(9 \%)$ were not treated by the court as drug court cases. During the three years following randomization, drug court cases originating in the Circuit Court averaged 720 days in the program while those originating in the District Court averaged 553 days. This finding is not surprising, as program length is expected to be longer for drug court participants handled by the Circuit Court as opposed to the District Court.

\section{Response to the initial arrest}

Table 1 shows the actual days incarcerated as a result of the initial arrest. The estimates of days incarcerated include all periods of incarceration in jail and prison occurring during the three-year follow-up period that were associated with the initial arrest. They capture time served as a direct result of the initial arrest (both pre- and post-disposition), as well as time served due to probation violations, where the term of probation was associated with the initial arrest. For drug court clients, the estimates also include temporary incarceration periods resulting from failure to comply with the requirements of the drug court (e.g., failure to appear for status hearings). The results are presented separately for each court, as experimental condition was found to interact with originating court for two of the measures included on the table.

Overall, similar percentages of drug court and control subjects were incarcerated as a result of the initial arrest (89.2\% vs. $83.3 \%)$. However, drug court subjects were incarcerated significantly more often during the follow-up than controls, averaging 2.3 episodes of incarceration. Despite this difference in the number of times incarcerated, the number of days incarcerated was not significantly different for drug court and control subjects (158.9 vs. 156.9 days). There was however, a large interaction of experimental condition and court. After three years, the District drug court cases wound up spending more than twice as many days incarcerated as their controls and almost as many days incarcerated as the Circuit drug court cases. This result is surprising given previously reported findings that in the Circuit Court, sentences were longer, and the treatment/control difference in the sentence to be served was larger, with control cases expected to spend more days incarcerated than drug court cases (Gottfredson and Exum 2002). Table 1 shows that when the number of incarceration days are separated out by reason, it appears that the difference between the courts in the use of incarceration is in large part explained by the difference between the courts in the use of incarceration in response to noncompliance. There is a large difference between the drug court and control cases in the use of incarceration for noncompliance in the District Court (a difference of 70.6 days) but not the Circuit Court (a difference of only 7.0 days). In short, incarceration was used a lot as a response in the District Court, resulting in more bed space being used by drug court offenders than by those who were processed as usual. 
DRUG TREATMENT COURT LONG-TERM OUTCOMES

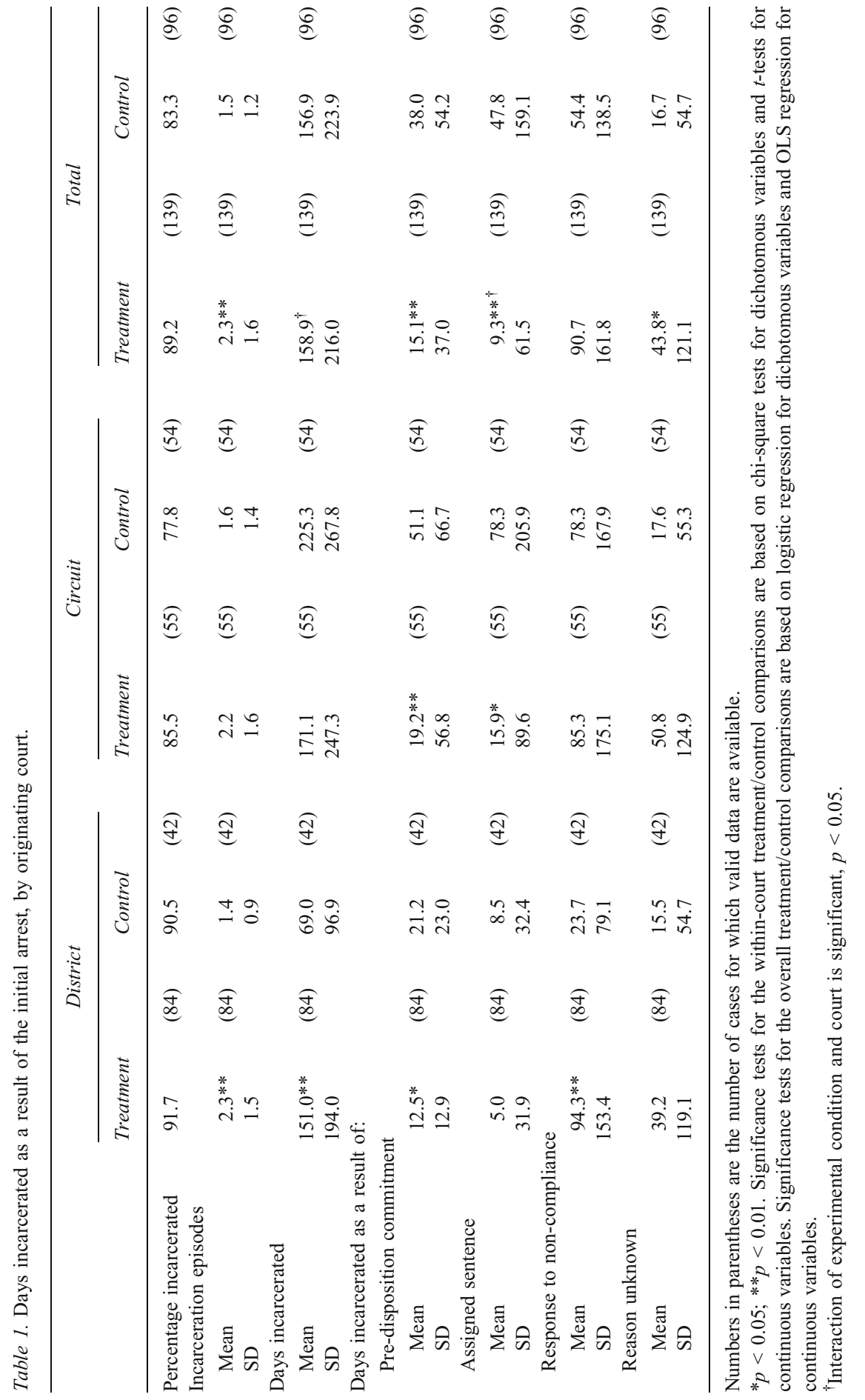




\section{Implementation of key program components}

Data on the level of implementation of the various drug court components, all based on existing court, parole/probation, and treatment records, suggest that the drug court program increased drug testing, judicial monitoring, and drug treatment for drug court clients relative to controls. Table 2 summarizes the amount of supervision (i.e., drug testing, judicial monitoring, and probation supervision) received by the study groups during the three-year follow-up period. Drug court subjects were significantly more likely than control subjects to have been drug tested and to have attended status hearings. Specifically, $86.9 \%$ of drug court subjects were tested for drugs, as compared to only $40.2 \%$ of control subjects, and $84.2 \%$ of drug court subjects attended at least one status hearing, as compared to only $7.3 \%$ of control subjects. In addition, the drug court cases attended a significantly greater number of status hearings than controls, and there was a significant interaction of experimental condition and court for the number of status hearings attended. In both the District Court and the Circuit Court, drug court clients attended a significantly greater number of status hearings than control cases. However, the treatment/control difference was larger among Circuit Court cases (a difference of 14.6 hearings) as compared to cases handled in the District Court (a difference of 6.5 hearings), and Circuit drug court cases on average attended twice as many hearings as District drug court cases (15.0 vs. 7.4). No

Table 2. Characteristics of supervision, three years after entry into study.

\begin{tabular}{|c|c|c|c|c|}
\hline \multirow[b]{3}{*}{ Percentage drug tested } & \multicolumn{4}{|c|}{ Experimental status } \\
\hline & \multicolumn{2}{|c|}{ Treatment } & \multicolumn{2}{|l|}{ Control } \\
\hline & $86.9 * *$ & $(130)$ & 40.2 & $(92)$ \\
\hline $\begin{array}{l}\text { Percentage with at least one hearing attended } \\
\text { Number of hearings attended }\end{array}$ & \multicolumn{3}{|c|}{ Number of hearings attended } & $(96)$ \\
\hline \multicolumn{5}{|l|}{ All subjects } \\
\hline Mean & $10.4^{* * \dagger}$ & $(139)$ & 0.6 & $(96)$ \\
\hline SD & 8.9 & & 2.4 & \\
\hline Percentage supervised & 83.3 & $(138)$ & 85.4 & $(96)$ \\
\hline \multicolumn{5}{|l|}{ Number of days supervised } \\
\hline \multicolumn{5}{|l|}{ All subjects } \\
\hline Mean & 445.5 & $(138)$ & 479.4 & $(96)$ \\
\hline $\mathrm{SD}$ & 326.5 & & 337.5 & \\
\hline \multicolumn{5}{|l|}{ Supervised subjects } \\
\hline Mean & 534.6 & $(115)$ & 561.3 & $(82)$ \\
\hline SD & 282.9 & & 295.1 & \\
\hline
\end{tabular}

Numbers in parentheses are the number of cases for which valid data are available.

$* * p<0.01$. Significance tests for the treatment/control comparisons are based on logistic regression for dichotomous variables and OLS regression for continuous variables.

${ }^{\dagger}$ Interaction of experimental condition and court is significant, $p<0.01$. 
differences were found on measures of probation supervision. ${ }^{7}$ Similar percentages of treatment and control subjects received probation supervision during the study period, and the two groups were similar with regard to the number of days supervised.

Table 3 summarizes the level of drug treatment services received by the study groups during the three-year follow-up period. In the BCDTC program, a jailbased acupuncture program is used as a sanction for relapsing subjects (Gottfredson et al. 2003c). This program, although considered a treatment, is not recognized as a certified drug treatment program by BSAS, the organization that coordinates drug treatment services in Baltimore. Therefore, it is separated in the table from the other certified drug treatments. The table shows that during the three years following entry into the study, $71.2 \%$ of the drug court group received some form of treatment, as compared with $27.1 \%$ of the control group $(p<.01)$. When only certified drug treatment is considered, the figures are $53.2 \%$ and $22.9 \%$

Table 3. Drug treatment experiences, three years after entry into study.

\begin{tabular}{|c|c|c|c|c|}
\hline & \multicolumn{4}{|c|}{ Experimental status } \\
\hline & Treatment & & Control & \\
\hline \multicolumn{5}{|l|}{ Percentage receiving } \\
\hline Any treatment & $71.2 * *$ & (139) & 27.1 & (96) \\
\hline Certified drug treatment & $53.2 * *$ & (139) & 22.9 & (96) \\
\hline Methadone maintenance & 7.2 & (139) & 9.4 & (96) \\
\hline Outpatient & $30.2 * *$ & (139) & 8.3 & (96) \\
\hline Residential & 10.1 & (139) & 7.3 & (96) \\
\hline Correctional & 2.2 & (139) & 0.0 & (96) \\
\hline Detoxification & 2.2 & (139) & 0.0 & (96) \\
\hline Intensive outpatient & $20.9 * *$ & (139) & 5.2 & (96) \\
\hline Other treatment & 2.2 & (139) & 0.0 & (96) \\
\hline Jail-based acupuncture & $48.9^{* *}$ & (139) & 8.3 & (96) \\
\hline \multicolumn{5}{|c|}{ Duration of treatment (any treatment) } \\
\hline \multicolumn{5}{|l|}{ All subjects } \\
\hline Mean & $139.8^{* *}$ & (139) & 48.4 & (96) \\
\hline SD & 187.0 & & 131.6 & \\
\hline \multicolumn{5}{|l|}{ Treated subjects } \\
\hline Mean & 196.3 & (99) & 178.7 & (26) \\
\hline SD & 195.0 & & 204.0 & \\
\hline \multicolumn{5}{|c|}{ Duration of treatment (certified treatment) } \\
\hline \multicolumn{5}{|l|}{ All subjects } \\
\hline Mean & $119.9^{* *}$ & (139) & 45.2 & (96) \\
\hline SD & 184.5 & & 130.5 & \\
\hline \multicolumn{5}{|l|}{ Treated subjects } \\
\hline Mean & 225.3 & (74) & 197.3 & (22) \\
\hline SD & 200.8 & & 213.6 & \\
\hline
\end{tabular}

Numbers in parentheses are the number of cases for which valid data are available.

${ }^{* *} p<0.01$. Significance tests for the treatment/control comparisons are based on logistic regression for dichotomous variables and OLS regression for continuous variables. 
$(p<.01) .{ }^{8}$ After jail-based acupuncture, the most common types of treatment for drug court participants were outpatient and intensive outpatient, and differences on these two treatment types were statistically significant. Among all subjects, the number of days in any treatment and the number of days in certified treatment were significantly higher for drug court cases. Drug court clients averaged 139.8 days in treatment, with 119.9 of these days devoted to certified treatment. Among subjects who received treatment, the number of days in treatment did not significantly differ by experimental status.

This variability in services received is exploited in a subsequent analysis examining the effects of different levels of service provision on recidivism.

\section{Recidivism}

Table 4 summarizes the recidivism outcomes of the study sample during the three years following the date of randomization into the study. The table also shows the $95 \%$ confidence intervals around each estimate. Prior to conducting the recidivism analysis, the two study groups were compared on the number of days at risk to reoffend during the follow-up. The comparison showed that the time at risk for a new arrest did not differ for drug court and control cases overall. However, there was an interaction of experimental condition and court. In the District Court, drug court cases were less at risk for a new arrest than controls, while in the Circuit Court, drug court cases were more at risk for a new arrest than controls. Because of this difference, both the mean number of new arrests and the mean number of new arrests per 1,000 days at risk are reported.

The figures presented in the table favor the drug court cases on nearly every measure, with comparisons producing significant differences on a number of the outcomes. Drug court subjects were less likely than control subjects to be rearrested, although this difference did not quite reach statistical significance ( $p=$ .05 ). Specifically, $78.4 \%$ of drug court and $87.5 \%$ of control subjects were rearrested. The number of new arrests was significantly lower for drug court cases as compared to controls ( 2.3 vs. 3.4 ), and this difference remained significant after factoring in time at risk for a new offense. When results are broken out by type of charge involved in the arrest, drug court subjects were less likely than controls to be arrested for every category of offense except weapons (in which the two groups were equal) and 'other' charges. However, the differences are statistically significant only for drug offenses.

In-program vs. post-program recidivism

The recidivism findings reported above indicate that the BCDTC is reducing crime. However, the outcomes presented in Table 4 do not differentiate in-program recidivism from post-program recidivism. Table 5 presents a comparison of DTC effects during and after the end of program services. This analysis speaks to the 
Table 4. Three-year recidivism outcomes.

\begin{tabular}{lll}
\hline & \multicolumn{2}{c}{ Experimental status } \\
\cline { 2 - 3 } & Treatment & Control \\
\hline Percentage re-arrested & $78.4(71.5-85.3)$ & $87.5(80.8-94.2)$ \\
Percentage re-convicted & $58.3(49.8-66.9)$ & $64.4(54.4-74.5)$ \\
Average number of new arrests & $2.3^{* *}(1.9-2.8)$ & $3.4(2.7-4.0)$ \\
Average number of new arrests per 1000 days at risk & $3.8^{* *}(2.9-4.6)$ & $5.8(4.3-7.3)$ \\
Average number of new charges & $4.4^{*}(3.4-5.4)$ & $6.1(4.8-7.4)$ \\
Average number of new convictions & $1.2(0.9-1.5)$ & $1.3(0.9-1.7)$ \\
Percentage of subjects with at least one new: & & \\
$\quad$ Violent or sex charge & $14.4(8.3-20.5)$ & $24.7(15.8-33.7)$ \\
Property charge & $35.1(26.9-43.3)$ & $40.4(30.3-50.5)$ \\
Drug charge & $55.5^{*}(47.1-63.9)$ & $68.4(58.9-77.9)$ \\
Prostitution/Solicitation charge & $5.3(1.4-9.2)$ & $6.7(1.4-11.9)$ \\
Public order charge & $36.0(27.9-44.2)$ & $46.3(36.1-56.5)$ \\
Weapons charge & $4.5(0.9-8.1)$ & $4.5(0.1-8.9)$ \\
Other charge & $1.5(-0.6-3.7)$ & $1.1(-1.1-3.4)$ \\
\hline
\end{tabular}

$95 \%$ confidence intervals appear in parentheses. Number of treatment subjects with valid data ranges from 124 to 139 . Number of control subjects with valid data ranges from 81 to 96 .

${ }^{*} p<0.05 ;{ }^{* *} p<0.01$. Significance tests for the treatment/control comparisons are based on logistic regression for dichotomous variables and OLS regression for continuous variables.

DTC model's ability to alter the behavior of its clients beyond the period during which services are provided. The table shows the mean number of arrests per 100 days at risk during participation in the drug court program as well as following participation. For the drug court cases, the three-year follow-up was divided into three periods: pre-program, in-program, and post-program. Comparable periods of time were established for the control cases using the mean number of days in each period for the drug court cases (namely, 26 days pre-program, 617 days inprogram, and 452 days post-program). Once the in-program and post-program periods were identified, the mean number of arrests was estimated for each, controlling for time at risk. The figures reported are limited to the drug court and control cases who were treated as randomized. That is, they exclude cases randomized to the drug court condition who were not dealt with in the drug court and cases randomized to the control condition who were dealt with in the drug court. In addition, the number of arrests per days at risk is based only on the subjects at risk for at least one day during the period of interest.

Table 5 shows that during both the in-program period and the post-program period, the drug court cases had fewer new arrests as compared to control cases. During their participation in the drug court, treatment cases averaged 0.45 arrests per 100 days at risk, while controls averaged 0.66 arrests during this same time period $(p<.05)$. Following their participation in the drug court, treatment cases averaged 0.32 arrests per 100 days at risk, while controls averaged 0.56 arrests $(p<$ $.05)$. The table also reports these differences expressed as standardized mean difference effect sizes. ${ }^{9}$ Effect sizes less than 0.20 are generally considered small. 
Table 5. In-program and post-program arrests.

\begin{tabular}{|c|c|c|c|c|c|c|}
\hline & \multicolumn{3}{|c|}{ In-program } & \multicolumn{3}{|c|}{ Post-program } \\
\hline & $\begin{array}{l}\text { Arrests } / 100 \\
\text { Days at risk }\end{array}$ & $N$ & $E S(T$ vs. C) & $\begin{array}{l}\text { Arrests } / 100 \\
\text { Days at risk }\end{array}$ & $N$ & $E S(T$ vs. $C)$ \\
\hline Treatment $^{\mathrm{b}}$ & $0.45^{*}$ & (125) & 0.26 & $0.32 *$ & $(90)$ & 0.32 \\
\hline Control $^{\mathrm{c}}$ & 0.66 & (88) & & 0.56 & $(80)$ & \\
\hline
\end{tabular}

${ }^{a}$ Includes only those subjects at risk for at least one day during the period of interest.

${ }^{b}$ Excludes subjects randomly assigned to the drug court who were not dealt with in the drug court.

${ }^{c}$ Excludes subjects randomly assigned to the control group who were dealt with in the drug court.

*Difference between treatment and control groups is significant, $p<0.05$. Significance tests based on OLS regression.

However, the practical significance of an effect size depends in large part on the seriousness of the outcome, since even small effects may lead to meaningful reductions in criminal behavior (Lipsey 1992). In this instance, the effect sizes are 0.26 for in-program arrests and 0.32 for post-program arrests. Taken together, these findings suggest that the effect of the BCDTC on recidivism is not limited to the period during which services are delivered, but rather, the effect persists after participation in the drug court program ceases.

\section{Recidivism as a function of level of implementation}

Variability in the amount of drug treatment, drug testing, judicial monitoring, and probation supervision received by the drug court subjects permits a comparison of the recidivism outcomes of clients who received more of these services with the outcomes of those who received less. To explore the relationship between participation in these four components and re-offending, categories reflecting varying levels of service were defined for each drug court component. For treatment, the categories are (1) 0 days of certified treatment, (2) 1 to 178 days of certified treatment, and (3) 179 or more days of certified treatment. Since a substantial number of subjects received no certified treatment, untreated subjects were placed in a single category. The median number of certified treatment days among subjects who received any treatment was used as the cut-point for defining the two groups of treated subjects. For drug testing, the categories are (1) 0 tests and (2) 1 or more tests, as the drug testing data available for the study only capture participation in drug testing. For status hearings, the categories are (1) 0 to 10 hearings attended and (2) 11 or more hearings attended. Finally, the categories for supervision are (1) 0 to 441 days of supervision and (2) 442 or more days of supervision. The categories for these last two program components were defined using the median value of the sample for each.

The association between level of participation in each of the four drug court components and mean number of arrests during the three year follow-up period, for 
the drug court cases only, is shown in Table 6. For all four components, subjects who received more services were re-arrested less often than subjects who received fewer services. Comparisons of the high implementation group with the lower implementation group(s) produced significant differences for three of the four program components. Specifically, drug court subjects in the high implementation categories for certified treatment, drug testing, and status hearings were re-arrested significantly less often than drug court subjects in the respective low implementation categories. ${ }^{10}$ In the case of probation supervision, subjects who were supervised 442 or more days recidivated less often than subjects who were supervised between 0 and 441 days, however this difference was not significant. The far right column of the table reports the differences between the highest implementation groups and the lower implementation groups expressed as standardized mean difference effect sizes. The effect sizes range from a low of 0.12 for arrests by amount of supervision, to a high of 1.37 for arrests by participation in drug testing.

These findings suggest that higher levels of implementation of the key drug court components are associated with larger reductions in recidivism. However, it is possible that the differences observed between the high and low implementation groups on mean arrests reflect selection bias rather than, or in addition to, effects of participation in the drug court services. That is, the relationship between higher levels of service and reduced recidivism may be due to unmeasured variables predicting both. To the extent that unmeasured variables influence both participation and recidivism, the effects of participation are overestimated in the results reported in Table 6. Several steps were taken to better understand the extent and consequences of selection bias. These additional analyses used both drug treatment court cases and control cases in order to make use of all of the available variation in the participation variables and to increase power.

First, we tested for endogeneity in equations predicting number of arrests from each of the three participation variables shown to be significantly related to recidivism in Table 6. Using OLS, we regressed the categorical ${ }^{11}$ versions of each of the three program components (status hearings, certified drug treatment, and drug testing) on the variable reflecting the random assignment to treatment or control, plus several control variables that might influence both recidivism and level of participation: originating court, age, gender, race, number of prior arrests, and number of days at risk for a new arrest. Residuals from these equations (representing unmeasured variables that influence participation) were then entered into OLS equations predicting number of arrests from each of the three participation variables (separately) as well as the same set of controls just listed. If the residuals from the first equation significantly predict the number of arrests, we have evidence of endogeneity in the equations of interest. The residuals from the status hearings and certified drug treatment equations were not significantly related to number of subsequent arrests, once the available controls were employed. This suggests that the unmeasured variables that determine the level of participation in these services are not related to the number of subsequent arrests, net of the available controls, and therefore OLS estimates of the effect of 
these components on recidivism will not be biased. The residuals from the drug testing equation were significantly related $(p<.05)$ to subsequent arrests (net of controls). However, when the other participation variables (certified drug treatment and status hearings) were entered into the equation as additional controls, the drug testing residual was no longer a significant predictor of recidivism. This suggests that OLS estimates of the effect of drug testing on recidivism will be biased unless they also control for participation in the other elements of the drug treatment court.

Table 7 contains the OLS estimates for the regression of number of arrests on each of the three participation variables, in separate equations. The models explain between 16 and $21 \%$ of the variance in number of subsequent arrests. In all three models, cases originating in the District Court, younger individuals, and individuals with more extensive criminal records had a higher number of subsequent arrests. Fewer days at risk was also significantly (or nearly so) related to the number of new arrests. The findings related to participation in the DTC

Table 7. OLS estimates of the effect of drug court implementation on the number of new arrests.

\begin{tabular}{|c|c|c|c|}
\hline Variable & Coeff. & $S E$ & Sig. \\
\hline Certified treatment (categorical measure) & -0.555 & 0.234 & 0.018 \\
\hline Court $(1=$ District, $0=$ Circuit $)$ & 0.852 & 0.361 & 0.019 \\
\hline Age & -0.091 & 0.025 & 0.000 \\
\hline Gender $(1=$ male, $0=$ female $)$ & -0.492 & 0.447 & 0.272 \\
\hline Race $(1=$ African American, $0=$ other $)$ & 0.804 & 0.633 & 0.206 \\
\hline Prior arrests & 0.079 & 0.023 & 0.001 \\
\hline Days at risk & -0.001 & 0.001 & 0.055 \\
\hline Intercept & 5.683 & 1.119 & 0.000 \\
\hline$R^{2}$ & 0.165 & & \\
\hline Status hearings (categorical measure) & -1.149 & 0.436 & 0.009 \\
\hline Court $(1=$ District, $0=$ Circuit $)$ & 0.790 & 0.362 & 0.030 \\
\hline Age & -0.091 & 0.025 & 0.000 \\
\hline Gender $(1=$ male, $0=$ female $)$ & -0.354 & 0.445 & 0.428 \\
\hline Race $(1=$ African American, $0=$ other $)$ & 0.798 & 0.629 & 0.206 \\
\hline Prior arrests & 0.082 & 0.023 & 0.000 \\
\hline Days at risk & -0.001 & 0.001 & 0.109 \\
\hline Intercept & 5.381 & 1.129 & 0.000 \\
\hline$R^{2}$ & 0.169 & & \\
\hline Drug testing (categorical measure) & -1.330 & 0.390 & 0.001 \\
\hline Court $(1=$ District, $0=$ Circuit $)$ & 1.052 & 0.365 & 0.004 \\
\hline Age & -0.101 & 0.025 & 0.000 \\
\hline Gender $(1=$ male, $0=$ female $)$ & -0.540 & 0.456 & 0.238 \\
\hline Race $(1=$ African American, $0=$ other $)$ & 0.862 & 0.670 & 0.200 \\
\hline Prior arrests & 0.086 & 0.024 & 0.000 \\
\hline Days at risk & -0.002 & 0.001 & 0.007 \\
\hline Intercept & 6.882 & 1.155 & 0.000 \\
\hline$R^{2}$ & 0.214 & & \\
\hline
\end{tabular}

Coeff. $=$ unstandardized regression coefficient; Sig. = significance of estimates.

$S E$ Standard error. 
components indicate that, for all three participation variables, the categorical variable measuring amount of service remained statistically significant after controlling for the background characteristics of the subjects, originating court, and days at risk for a new arrest. As we have shown, however, the OLS regression for drug testing may overestimate the effects of drug testing on arrest because unmeasured variables, specifically, participation in drug treatment and status hearings, are related both to the number of arrests and participation in drug testing.

A logical next step would be to estimate OLS equations regressing number of arrests on all three of the participation variables simultaneously. This would presumably correct for the endogeneity problem in the drug testing equation, and provide cleaner estimates of the effect of each of the three components. However, examination of the inter-correlations among the participation variables and their correlations with the dependent variable of interest made clear that any attempt to estimate separate effects for these components would be futile. ${ }^{12}$ Participation in drug testing, status hearings, and certified treatment are moderately correlated ( $r$ 's range from 0.43 to 0.47 ), while their correlations with number of arrests are low (ranging from -0.22 to -0.24 ).

An alternative approach to estimating the effects of participation recognizes that the three services act more as a 'package' than as individual components. We therefore created a composite participation variable that is simply the sum of the three categorical participation variables. This treatment composite ranges from zero $(28.5 \%)$, representing individuals who received none of the three services, to four $(13.2 \%)$, representing individuals who participated in drug testing, 11 or more status hearings, and 179 or more days of certified drug treatment. Again, both treatment and control subjects are included in these analyses.

The OLS regressions described above were repeated with this composite participation variable to examine the extent to which endogeneity would be expected to bias the OLS regression coefficient relating participation to recidivism. These analyses indicated that the residuals from the first stage equation predicting participation did significantly predict the number of arrests, net of the same control variables. OLS regression would therefore not be expected to produce unbiased estimates of the effect of the composite participation measure.

Following Angrist (2005), we estimated the effects of the composite participation variable on the number of arrests in the follow-up period using an IV approach as described in the Methods section. Table 8 shows the results of the 2SLS analyses, and shows the corresponding OLS equation for comparison. The 2SLS estimate for the level of participation in drug treatment court services was statistically significant $(p<.01)$ and in the anticipated direction. Also, cases originating in the Circuit Court, younger individuals, and individuals with a larger number of prior arrests had more arrests during the follow-up period. The corresponding OLS equation results lead to the same conclusion.

The findings concerning the relationship between program services and recidivism suggest that as drug court program services increased, the number of arrests for a new offense decreased. 
Table 8. 2SLS and OLS estimates of the effect of composite drug court implementation on the number of new arrests.

\begin{tabular}{|c|c|c|c|}
\hline Variable & Coeff. & $S E$ & Sig. \\
\hline \multicolumn{4}{|l|}{ 2SLS estimates: } \\
\hline Composite participation & -0.748 & 0.248 & 0.003 \\
\hline Court $(1=$ District, $0=$ Circuit $)$ & 0.913 & 0.372 & 0.015 \\
\hline Age & -0.102 & 0.026 & 0.000 \\
\hline Gender $(1=$ male, $0=$ female $)$ & -0.537 & 0.460 & 0.244 \\
\hline Race $(1=$ African American, $0=$ other $)$ & 1.241 & 0.708 & 0.081 \\
\hline Prior arrests & 0.089 & 0.024 & 0.000 \\
\hline Days at risk & -0.001 & 0.001 & 0.292 \\
\hline Intercept & 6.008 & 1.170 & 0.000 \\
\hline$R^{2}$ & 0.205 & & \\
\hline \multicolumn{4}{|l|}{ OLS estimates: } \\
\hline Composite participation & -0.481 & 0.138 & 0.001 \\
\hline Court $(1=$ District, $0=$ Circuit $)$ & 0.970 & 0.366 & 0.009 \\
\hline Age & -0.103 & 0.025 & 0.000 \\
\hline Gender $(1=$ male, $0=$ female $)$ & -0.519 & 0.455 & 0.256 \\
\hline Race $(1=$ African American, $0=$ other $)$ & 0.988 & 0.675 & 0.145 \\
\hline Prior arrests & 0.088 & 0.024 & 0.000 \\
\hline Days at risk & -0.001 & 0.001 & 0.077 \\
\hline Intercept & 6.183 & 1.152 & 0.000 \\
\hline$R^{2}$ & 0.216 & & \\
\hline
\end{tabular}

Coeff. = unstandardized regression coefficient; Sig.= significance of estimates SE Standard error.

\section{Discussion}

Earlier reports from the evaluation of the BCDTC program showed that the program was reducing criminal offending in a population of drug-addicted, chronic offenders. This research (Banks and Gottfredson 2003, 2004; Gottfredson and Exum 2002; Gottfredson et al. 2003a, c) showed a 15 to $16 \%$ point differential favoring the treatment subjects on re-arrest up to two years after randomization, and that these positive results on official measures of recidivism replicate using self-reports. These positive effects on recidivism are in line with results from a meta-analysis of 41 evaluations of drug treatment courts which shows, on average, a 14 percentage point recidivism differential favoring drug treatment courts, with a slightly larger effect for drug-related crimes than for other crimes (Wilson et al. 2002).

Results from the current study add to this body of knowledge about DTC effects. Findings from the third year of the study reported herein showed sustained treatment differences with regard to recidivism. New arrests (2.3 vs. 3.4) were significantly lower for treatment than control group members, and this finding remained significant after adjusting for time at risk. In addition, drug court cases had significantly fewer charges than controls (4.4 vs. 6.1) and were significantly less likely to have been arrested for a drug offense. The positive effects on 
recidivism were also found to extend past the offenders' involvement in the BCDTC. Drug court cases had significantly fewer new arrests as compared to control cases following their participation in the drug court, with treatment cases averaging 0.32 arrests per 100 days at risk, while control cases averaged 0.56 arrests. These positive findings are tempered with findings that more than threefourths of clients were re-arrested within three years, regardless of participation in the drug treatment court, and that drug treatment court cases spent approximately the same number of days incarcerated as control cases. Also, although drug court subjects were less likely than controls to be arrested for most types of offenses, the differences were statistically significant only for drug offenses.

Although results from the BCDTC suggest that the program is effective, the data on the level of services reveals considerable variability across clients in services received. One indication that many clients did not receive the full programs as intended is the fact that by the end of the three-year follow-up period, less than a third $(31 \%)$ of the drug court cases had graduated from drug court. The largest percentage of clients $(45 \%)$ was terminated from the drug court before receiving the full compliment of services.

Data on the level of implementation of the various drug court components shows a great deal of variability across clients in the amount of services received. Although a higher percentage of DTC clients than control cases were drug tested, attended status hearings, and received drug treatment, the levels of some of these services were not uniformly high for all DTC clients. Specifically, although $84.2 \%$ of drug court subjects attended at least one status hearing, the number attended fell short of expectation: Circuit drug court cases on average attended 15.0 judicial hearings, and District drug court cases on average attended 7.4. 71.2\% of the drug court group received some form of treatment, and $53.2 \%$ of the drug court group received certified drug treatment. Among those drug court clients who received any certified drug treatment, the average number of days of treatment was 225.3, or 7.5 months. Importantly, however, reductions in recidivism were achieved despite imperfect implementation of the DTC components.

Of special concern is the finding that while drug court cases had fewer new arrests and new charges than controls, these positive outcomes did not result in overall differences in incarceration time between the two conditions. In fact, in the District Court, drug court cases wound up spending more than twice as many days incarcerated as controls. These findings suggest that although the drug court model is effective for reducing crime, the dollar savings expected to accrue from less incarceration time for drug court clients are not necessarily realized. Belenko's (2001) review of cost analyses of DTCs found that per client DTC costs were generally less than per client standard processing costs, but that this cost savings came primarily from reduced incarceration. The BCDTC experience suggests that DTCs may actually be more costly than standard processing if incarceration is not more effectively reduced.

Prior research had also suggested that that there is much variability in the quality of services received by DTC clients, and that receiving drug treatment may be important. The research, however, failed to rule out selection effects as an 
alternative explanation for the better outcomes observed for subjects who happened to receive more drug treatment services. Results presented here allow for a more confident conclusion that the major components of DTCs - drug testing, status hearings, and certified drug treatment - are responsible for a reduction in the number of subsequent arrests. Within-treatment group comparisons of re-arrests by level of participation showed the expected association within the treatment group. OLS regressions using both treatment and control subjects and controlling for several covariates showed that higher levels of drug testing, status hearings, and certified drug treatment are related to fewer subsequent arrests, but these analyses are partly confounded by unmeasured predictors of both participation and subsequent arrest. Instrumental Variables analysis confirmed that a higher level of participation in the three components induced by random assignment produces a reduction in the number of arrests. These findings strongly suggest that if the BCDTC could find ways to induce greater client participation in the main components of the program, stronger effects on recidivism would be realized.

\section{Limitations}

The results reported herein are subject to a number of limitations. First, the study pertains to a specific DTC at a specific point in time during the evolution of that court (beginning at approximately three years after the program began, and extending, for the average participant, for 22 months during which services were provided). DTCs are heterogeneous in terms of the populations served, the point at which they involve offenders (e.g., pretrial, post-conviction), and the emphasis placed on certain components. Also, as Goldkamp et al. (2001a, b) demonstrate, DTCs evolve over time, and effects are sometimes dependent upon the timing of the evaluation study. Our study clearly does not generalize to courts unlike the BCDTC, and, although our prior study of the first year of the BCDTC (Gottfredson et al. 1997) also found positive results, it is possible that a study conducted on today's court would not. Results also do not necessarily generalize to different client populations than the one studied here.

Although this study attempted to measure the services actually received through the DTC program, our measures were cursory. This limitation stems from the fact that we relied upon existing data sources to capture participation in the major components of the program. Our only measures of services provided included the number of status hearings attended (e.g., nothing about the content or quality of these sessions), whether or not the client participated at all in drug testing, the number of days of probation supervision, and the number of days and type of drug treatment. Prior research (Goldkamp et al. 2001a, b) on DTCs demonstrated that time in treatment-type measures of substance abuse treatment are not as sensitive as are measures of the number of actual treatment contacts. Although we find effects using the available measures, it is likely that more sensitive measures would perform better.

Another limitation in the segment of the study that relates DTC program participation with subsequent arrests is that the timing of the participation variables 
relative to the recidivism is not captured. We measured the number of status hearings attended and the number of days of drug treatment, and we measured the number of arrests during the follow-up period. We interpreted the observed association between the measures of participation and arrest to mean that participation decreases arrest. However, it is not possible based on the analyses presented here to rule out the alternative interpretation that re-arrest leads to a reduction in participation. Fortunately, prior reports from the BCDTC study using survival analyses and time-varying predictors of time to re-arrest demonstrated (at least up until 24 months following random assignment) that attending drug treatment during the preceding month predicted survival time (Banks and Gottfredson 2003). Because most of the BCDTC services were provided during the first 24 months of the follow-up period, we are confident that the associations we observe between participation and arrest during the 36-month follow-up period do not reflect primarily an effect of arrest on participation.

Another limitation of the study is its inability to separate out the effects of the various DTC components on recidivism. This limitation applies to any study of a multi-component program in which the components are offered as a package. Subjects who receive one component are highly likely to receive others. This fact makes it impossible to estimate the effects of each component separately. To do so would require a design that deliberately assigns subjects to receive some components and not others. Because the DTC design includes an array of different services, it is unlikely that research on DTCs will ever yield this type of information.

Finally, certain caveats apply to the IV analysis. Using the randomization outcome as an instrument to correct for endogeneity problems in the estimation of the effects of participation requires certain assumptions: (1) The disturbance on the dependent variable must be independent of the IV; and (2) the IV must effect the dependent variable only via the problematic (endogenous) variable. These assumptions seem tenable in our analysis. The first is true by definition, given that our IV is a random variable. The second assumption is more difficult because one can imagine that there may be other consequences of random assignment (aside from elevated participation in certified drug treatment, status hearings, and drug testing) that influence subsequent recidivism. Factors such as the use of longer suspended sentences or more frequent sanctions in response to misbehavior for the DTC cases may indeed influence later arrests. Another limitation of the IV approach is that the meaning of the participation variable is to some extent changed when it is re-created using predicted values from a regression based on random assignment. The corrected participation variable captures only participation in DTC components that can be induced through random assignment. As Angrist (2005) points out, variability in participation due to persons who would always participate or never participate, regardless of random assignment, is removed from the IV analysis. The results therefore pertain only to subjects whose participation level can be influenced by random assignment.

Despite these limitations, the results of this study suggest that DTCs are effective, but that they can be made even more effective if (a) the level of par- 
ticipation in key services can be increased and (b) the use of incarceration as a sanction can be decreased. An incentive structure that explicitly rewards attendance at drug treatment and status hearings and participation in drug testing might be helpful. Also, BCDTC subjects reported in interviews that more job placement and housing assistance would improve their treatment programs (Gottfredson et al. 2003b). Enhancing treatment services in these ways might also improve treatment retention.

Our study showed great variability across the two different courts included in our study in the use of incarceration as a sanction. The District Court's high use of incarceration resulted in more bed space being used by drug court offenders than by those who were processed as usual. This seemingly unbridled use of judicial discretion in the use of incarceration as a DTC sanction should be the subject of scrutiny and debate. DTCs should closely monitor and attempt to rationalize their use of sanctions.

\section{Acknowledgments}

Support for this research was provided by the Maryland Department of Public Safety and Correctional Services. Points of view or opinions contained in this document are those of the authors and do not necessarily represent the official position or policies of the Maryland Department of Public Safety and Correctional Services. The authors appreciate the assistance of Judith Sachwald, Thomas H. Williams, Patrick McGee, Raymond Sheaffer, Glendell Adamson, Dave Pinter, Robb McFaul, Scott Eastman, Ellen Talley, Gwen Rice, Gwendolyn Smith, Denise Smith and John Eversley of the Maryland Division of Parole and Probation; Alan Woods, Deborah Herman, Paige Croyder, and Patsy Caron of the State's Attorney's Office; Leonard Kuentz and Gary Woodruff of the Office of the Public Defender; the Honorable Judges Jamey Weitzman and Thomas Noel; and the staff of several treatment providers involved in the study. We also wish to thank Todd A. Armstrong, Duren Banks, Joseph Cooke, M. Lyn Exum, Qianwei $\mathrm{Fu}$, and John T. Ridgely for research assistance, and Jeff Smith for teaching us about instrumental variables. Three anonymous reviewers, Josh Angrist, and David Weisburd also provided comments that vastly improved our work.

\section{Notes}

1 The following description of the Baltimore City Drug Treatment Court is taken with minor revision from an earlier description (Gottfredson et al. 2003c).

2 In some instances, records from different sources overlapped when it did not make sense for them to do so (e.g., probation records overlapping with incarceration records). These inconsistencies were resolved by checking the conflicting records against all other available sources of data and making an informed judgment regarding what most likely occurred. 
3 These means and proportions were estimated using both unweighted data and data weighted according to originating court. For the latter, all subjects originating in the Circuit Court were given a weight of 1 , as these cases were randomly assigned to the drug court and control conditions using a one-to-one ratio. In comparison, District Court cases were randomly assigned using a two-to-one ratio. Since this resulted in a drug court sample twice the size of the control sample, individuals in the control sample were given twice as much weight in the weighted analyses. Specifically, control subjects were given a weight of 1.5 and drug court subjects were given a weight of .75 . These weight values were used (as opposed to 2 and 1) because they produced a weighted sample size equal to the unweighted sample size $(N=235)$ while creating roughly equal numbers in the drug court $(N=118)$ and control $(N=117)$ samples. The weighted and unweighted means and proportions were similar. For example, mean arrests for the drug court and control groups using the unweighted data were 2.3 and 3.4, respectively, compared with 2.3 and 3.5 using the weighted data. Thus, only the unweighted means and proportions are presented here.

4 In econometric terminology, the independent variable of interest is therefore 'endogenous.'

5 'Consistency' is achieved when the sample statistic converges to the true population parameter as the sample size increases.

6 As will be described later, the separate participation variables are combined into one composite measure of participation for the IV analysis.

7 Probation supervision here refers to all supervision that occurred during the three years following randomization and not just the probation supervision resulting from the initial arrest.

8 The percentage of drug court subjects who actually received drug treatment has been the subject of much debate. This report identifies a subject as having received treatment only if (a) a record of certified treatment was found for that subject in the BSAS computerized database or (b) a record of acupuncture services was found at the Baltimore City Detention Center. The drug court judges contend that actual treatment rates are substantially higher than these records indicate. The judges' review of court 'bench notes' (court records of what occurred at judicial hearings) indicate that many of the subjects for whom no BSAS record of treatment was found did receive at least some treatment. The discrepancies between the bench notes and the BSAS records might be due to one or more of the following reasons: (1) Only certified drug treatment is included in the BSAS files; The bench note records frequently indicate non-certified treatment. (2) Some certified treatment providers wait until the second or third visit to officially admit a case into treatment because they expect a high degree of attrition after the first visit. Official intake triggers a BSAS record. Several of the subjects recorded as having received treatment in the bench notes probably attended only one or two sessions and therefore were never officially admitted. (3) Some treatment providers have waiting lists. Subjects show up for treatment but are told they must wait. Many never return. These subjects may be recorded in the bench notes as having received treatment on the basis of their initial visit. (4) At least one treatment provider runs a 'pre-admission' group for clients as they wait for actual treatment. These subjects may be recorded as receiving treatment in the bench notes because they are attending a group run by a treatment provider, even though these group sessions in fact did not provide substance abuse treatment. (5) BSAS records may exist under a different name for some cases. Several different matching procedures using names, aliases, and demographic characteristics were used, but it remains possible that some valid treatment records were missed. (6) 
Subject reports of treatment at the time of the court hearing may be erroneous. These reports are not always verified with the treatment provider. Because it is not possible to determine which of these factors may be operating to produce discrepancies between the official BSAS records of treatment and the judges' records, the rates of treatment reported herein should be regarded as lower bound estimates of the actual amount of treatment received.

9 The standardized mean difference effect size is a measure of the difference between treatment and comparison groups relative to the standard deviation of the measure employed (Lipsey and Wilson 2001).

10 In response to concerns (see footnote 8) that the official records of treatment may not be complete, we repeated this analysis using a dummy variable in which subjects who were either found to have received drug treatment in the official records or who self-reported having received drug treatment in interviews conducted during the follow-up period (see Gottfredson et al. 2003b for details on the methodology used in this study) were coded as having received treatment and those who neither self-reported receiving drug treatment nor were found in the official records were coded as not having received treatment. This analysis replicated the pattern of findings based on the analysis of official records only.

11 The drug testing variable is a binary measure. The status hearing and certified treatment variables are continuous, but their distributions are clumpy, with a large percentage of zeros ( $47 \%$ for hearings and $59 \%$ for treatment). The treatment variable also has high kurtosis. Therefore the categorical forms of these variables described and used in Table 6 earlier are used in all regression analyses.

12 Indeed, an attempt to estimate the effects of the three components while controlling on the other components results in inflated standard errors for the regression coefficients and a solution that is not credible.

\section{References}

Anglin, D. M. \& Hser, Y. (1990). Legal coercion and drug abuse treatment: Research findings and social policy implications. In J. A. Inciardi (Ed.), Handbook of drug control in the United States. Westport, CT: Greenwood.

Angrist, J. D. (2005). Instrumental variable methods in experimental criminological research: What, why and how. Available at http://www.nber.org/papers/t0314.

Banks, D. \& Gottfredson, D. C. (2003). The effects of drug treatment and supervision on time to re-arrest among drug treatment court participants. Journal of Drug Issues 33(2), 385-412.

Banks, D. \& Gottfredson, D. C. (2004). Participation in drug treatment court and time to rearrest. Justice Quarterly 21(3), 637-658.

Bar Association of Baltimore City (1990). The drug crisis and underfunding of the justice system in Baltimore city. Report of the Russell Committee 9.

Belenko, S. (1993). Crack and the evolution of anti-drug policy. Contributions in Criminology and Penology 42(10), 13-15.

Belenko, S. (1998). Research on drug courts: A critical review. National Drug Court Institute Review I(1), 1-42.

Belenko, S. (1999). Research on drug courts: A critical review, 1999 update. National Drug Court Institute Review II(2), 1-58. 
Belenko, S. (2001). Research on drug courts: A critical review, 2001 update. New York: The National Center on Addiction and Substance Abuse at Columbia University.

Collins, J. J. \& Allison, B. (1983). Legal coercion and retention in drug abuse treatment. Hospital Community Psychiatry 34, 1145-1149.

Cooper, C. S. (1997). Drug court survey report: Executive summary. Available Online: http://www.american.edu/academic.depts/spa/justice/publications/exec1.htm.

Deschenes, E. P., Turner, S. \& Greenwood, P. W. (1995). Drug court or probation? An experimental evaluation of Maricopa County's drug court. The Justice System Journal 18, $55-73$.

Drug Courts Program Office (1997). Defining drug courts: The key components. Washington, D.C.: U.S. Department of Justice, Office of Justice Programs.

Finigan, M. W. (1999). Assessing cost off-sets in a drug court setting. National Drug Court Institute Review 15(1), 41-51.

Foster, E. M. \& McLanahan, S. (1996). An illustration of the use of instrumental variables: Do neighborhood conditions affect a young person's chance of finishing high school? Psychological Methods 1, 249-260.

Goldkamp, J. S. \& Weiland, D. (1993). Assessing the impact of Dade County's felony drug court: Research in brief. Washington, D.C.: U.S. Department of Justice, National Institute of Justice.

Goldkamp, J. S., White, M. D. \& Robinson, J. B. (2001a). Context and change: The evolution of pioneering drug courts in Portland and Las Vegas (1991-1998). Law \& Policy 23(2), 143-170.

Goldkamp, J. S., White, M. D. \& Robinson, J. B. (2001b). Do drug courts work? Getting inside the drug court black box. Journal of Drug Issues 31, $27-72$.

Gottfredson, D. C. \& Exum, L. M. (2002). The Baltimore City Drug Treatment Court: Oneyear results from a randomized study. Journal of Research in Crime and Delinquency 39, $337-356$.

Gottfredson, D. C., Coblentz, K., \& Harmon, M. A. (1997). A short-term outcome evaluation of the Baltimore City Drug Treatment Court program. Perspectives, Winter: 33-38.

Gottfredson, D. C., Kearley, B. W., Najaka, S. S. \& Rocha, C. M. (2003a). The Baltimore City Drug Treatment Court: Three-year self-report outcome study. Evaluation Review 29(1), 42-64.

Gottfredson, D. C., Kearley, B., Najaka, S. S. \& Rocha, C. (2003b). Baltimore City Drug Treatment Court: Evaluation of client self-reports at three-year follow-up. Technical report available from the authors.

Gottfredson, D. C., Najaka, S. S. \& Kearley, B. (2003c). Effectiveness of drug treatment courts: Evidence from a randomized trial. Criminology and Public Policy 2(2), 171-196.

Hare, R. D., Harpur, T. J., Hakstian, A. R., Forth, A. E., Hart, S. D. \& Newman, J. P. (1990). The revised Psychopathy Checklist: Reliability and factor structure. Psychological Assessment 2, 338-341.

Harrell, A., Cavanagh, S. \& Roman, J. (1998). Findings from the evaluation of the D.C. Superior Court Drug Intervention Program: Final report. Washington, D.C.: The Urban Institute.

Harrison, L. D. \& Scarpitti, F. R. (2002). Drug treatment courts: Progress and issues. Substance Use and Misuse 37, 1441-1467.

Hora, P. F., Schma, W. G. \& Rosenthal, J. T. (1999). Therapeutic jurisprudence and the drug treatment court movement: Revolutionizing the criminal justice system's response to drug abuse and crime in America. Notre Dame Law Review 74(2), 439-538. 
Lipsey, M. W. (1992). Juvenile delinquency treatment: A meta-analytic inquiry into the variability of effects. In T. D. Cook, H. Cooper, D. S. Cordray, H. Hartmann, L. V. Hedges, R. J. Light, T. A. Louis \& F. Mosteller (Eds.), Meta-analysis for explanation (pp. 83-127). New York: Russell Sage Foundation.

Lipsey, M. W. \& Wilson, D. B. (2001). Practical meta-analysis. Thousand Oaks, CA: Sage. Longshore, D., Turner, S., Wenzel, S., Morral, A., Harrell, A., McBride, D., Deschenes, E. \& Iguchi, M. (2001). Drug courts: A conceptual framework. Journal of Drug Issues 31, $7-26$.

McColl, W. D. (1996). Baltimore City's Drug Treatment Court: Theory and practice in an emerging field. Maryland Law Review 55(2), 467-518.

McLellan, A. T., Kushner, H., Metzger, D., Peters, R., Smith, I., Grissom, G., Pettinati, H. \& Argeriou, M. (1992). The fifth edition of the Addiction Severity Index. Journal of Substance Abuse Treatment 9, 199-213.

Office of Justice Programs Drug Court Clearinghouse and Technical Assistance Project (2001). Drug court activity update: Summary information on all programs and detailed information on adult drug courts, June, 2001. Available Online: http://www.american. edu/academic.depts/spa/justice/publications/allcourtactivity.pdf.

Office of Justice Programs Drug Court Clearinghouse and Technical Assistance Project (2004). Summary of drug court activity by state and county, May, 2004. Available Online: http://www.american.edu/academic.depts/spa/justice/publications/drugchart2k.pdf.

Peters, R. H. \& Murrin, M. R. (1998). Evaluation of Treatment-Based Drug Courts in Florida's First Judicial Circuit. Tampa, FL: Department of Mental Health, Law and Policy, Louis de la Parte Florida Mental Health Institute, University of South Florida.

Sechrest, D. K., Shichor, D., Artist, K. \& Briceno, G. (1998). The Riverside County Drug Court: Final research report for the Riverside County Probation Department. Riverside County, CA: California State University, Criminal Justice Department, San Bernardino, CA.

Spohn, C., Piper, R. K., Martin, T. \& Frenzel, E. D. (2001). Drug courts and recidivism: The results of an evaluation using two comparison groups and multiple indicators of recidivism. Journal of Drug Issues 31, 149-196.

Tonry, M. (1995). Malign neglect: Race, crime, and punishment in America. New York: Oxford University Press.

U.S. Department of Justice (1998). Looking at a decade of drug courts. NCJ 171140. Washington, D.C.: U.S. Department of Justice.

U.S. General Accounting Office (1997). Drug courts: Overview of growth, characteristics, and results. Washington, D.C.: U.S. General Accounting Office.

U.S. General Accounting Office (2002). Drug courts: Better DOJ data collection and evaluation efforts needed to measure impact of drug court programs. Washington, D.C.: U.S. General Accounting Office.

Wilson, D. B., Mitchell, O. \& MacKenzie, D. (2002). A systematic review of drug court effects on recidivism. Paper presented at the annual meeting of the American Society of Criminology, Chicago, IL.

Wish, E. D. \& Johnson, B. D. (1986). The impact of substance abuse on criminal careers. In A. Blumstein, J. Cohen, J. A. Roth \& C. A. Visher (Eds.), Criminal careers and "career criminals" (Vol. 2). Washington, D.C.: National Academy.

Wooldridge, J. M. (2002). Econometric analysis of cross-section and panel data. Cambridge, MA: The MIT Press. 


\section{About the authors}

Denise C. Gottfredson is a Professor at the University of Maryland Department of Criminal Justice and Criminology. She received a PhD in Social Relations from The Johns Hopkins University, where she specialized in Sociology of Education. D. Gottfredson's research interests include delinquency and delinquency prevention, and particularly the effects of school environments on youth behavior. Gottfredson has recently completed randomized experiments to test the effectiveness of the Baltimore City Drug Treatment Court and the Strengthening Families Program in Washington D.C. She is currently directing a randomized trial of the effects of after school programs on the development of problem behavior.

Stacy Skroban Najaka is the Research Director of the Maryland State Commission on Criminal Sentencing Policy. She received a $\mathrm{PhD}$ in Criminology and Criminal Justice from the University of Maryland. Prior to joining the Commission in 2005, Dr. Najaka was a Research Associate at the University of Maryland where she directed a meta-analytic study of prevention and intervention strategies throughout Maryland, managed a randomized study of the Baltimore City Drug Treatment Court, and assisted Maryland's Division of Parole and Probation in improving the design and use of its data systems to enhance the supervision of offenders. Her current research interests include program and policy evaluation and research methods.

Brook Kearley is a Research Associate at Social Solutions International. Her primary research interests include the evaluation of drug treatment processes and outcomes, the organization of service delivery systems, and research methods. Ms. Kearley has managed several federal and state funded studies that examined the efficacy of drug treatment strategies and she has collaborated on numerous publications related to drug treatment court outcomes, the impact of mediating variables on drug treatment outcomes, and the validity of self-reported drug use and crime. She received her Master's degree in Criminology and Criminal Justice from the University of Maryland.

Carlos M. Rocha is a doctoral candidate in the Department of Criminology and Criminal Justice at the University of Maryland, College Park. His doctoral dissertation examines the survival rates by treatment modality of offenders randomized into the Baltimore City Drug Treatment Court evaluation. Mr. Rocha is also interested in the experience of Latinos in the criminal justice system and the effects of acculturation on crime. 
Copyright of Journal of Experimental Criminology is the property of Springer Science \& Business Media B.V. and its content may not be copied or emailed to multiple sites or posted to a listserv without the copyright holder's express written permission. However, users may print, download, or email articles for individual use. 